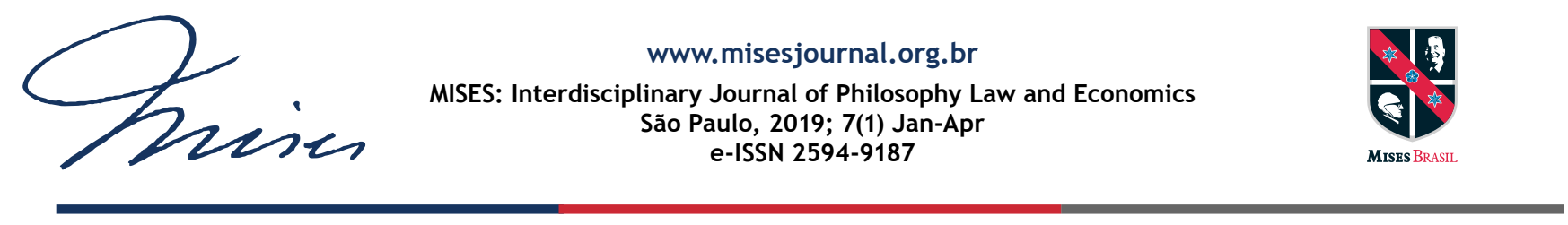

\title{
O Intelectual e o Nada
}

\author{
João Pinheiro Silva*
}

SCRUTON, Roger. Impostores e Incendiários - Os Pensadores da Nova Esquerda. Lisboa: Quetzal Editores, 2010. 400 p.

De quando em quando, entre Žižek e Piketty, um lapso de lucidez assola as editoras nacionais. Foi a vez de Tolos, Impostores e Incendiários - Os Pensadores da Nova Esquerda, livro que nasce da reedição de Thinkers of the New Left, de 1985, obra seminal de Roger Scruton e que lhe rendeu o começo da marginalização intelectual com a qual lidou nos anos 1980 e 1990.

A quatro anos da queda do muro de Berlim, o livro surgira como um verdadeiro crepúsculo dos ídolos, no qual os ícones intelectuais da época eram desmantelados, um a um, pelo filósofo britânico. Como um bom antifrágil, ainda que longe da academia, Scruton construiu um sólido e bem sucedido percurso intelectual, tornando-se uma espécie de guru da Direita britânica (e não só) pós-Thatcher. Explico este fenômeno com o seu estilo elegante (fenômeno raro entre a intelligentsia contemporânea que, como é demonstrado no livro, prefere embaciar seus textos com verborreia ininteligível, na esperança de ocultar o nada que os premia), adornado com fina ironia, juntamente com a erudição que acompanha cada uma de suas meditações.

Scruton é um polímata e, acima de tudo, um polígrafo (em todos os sentidos da palavra), características que ficam claras ao longo de toda a obra. O seu intelecto viaja entre tradições filosóficas, literárias e culturais de modo a construir, usando a expressão de Foucault, uma "arqueologia do saber", neste caso, uma "arqueologia da revolução". Este é, creio, o ponto chave do livro e o conceito que une toda esta massa de pensadores (ou pretensos pensadores) analisados: a revolução.

Ainda que hegeliano (com nuances, pelo menos), Scruton não é Fukuyama e sabe muito bem que a queda do muro de Berlim não representa o sonho de uma esquerda ajoelhada perante a democracia liberal, reconhecendo suas virtudes. Se esteve de joelhos, ergueu-se depressa e nem deu tempo para respirar. Lacan, Foucault, Habermas, Said, Badiou e companhia foram elevados

DOI https://doi.org/10.30800/mises.2019.v7.1133

* Licenciando em Filosofia na FLUP, autor no blog O Insurgente. E-mail: silvajoao1999@gmail.com 
a autores canônicos, imprescindíveis no currículo do aluno de humanidades. $\mathrm{O}$ inteligente do século XXI tem de conhecer estes nomes, venerar estes nomes, reiterar sua verborreia e discorrer sobre ela em teses repletas de seus, usando o termo de Scruton, "absurdemas". A reedição da obra surge, deste modo, como uma resposta a uma demanda real e urgente: a demanda por sanidade.

O livro não é, ao contrário do que acontece nos círculos dos intelectuais citados, uma masturbação ideológica onde a crítica ao inimigo suplanta a discussão racional. Com raras exceções, Scruton faz um elogio do pensador analisado. Apenas Lacan, Badiou e Althusser escapam ilesos e, creio, felizes pelo sucedido. Falo de pensadores onde a redução ao absurdo pode ser facilmente substituída pela simples enunciação de suas teorias. Estamos perante o apogeu de todo um projeto, um projeto onde "o pensamento e o não-pensamento" competem em pé de igualdade, onde a "validade, a verdade e o argumento racional são cancelados num ápice". O maior mérito de Scruton é trazer das profundezas do absurdo, a origem de tais delírios ajaezados.

Edmund Burke definiu o jacobinismo (e parentes de seu tempo) como "teoria de gabinete". O intelectual de gabinete é aquele, grosso modo, que tenta enquadrar a existência num esquema teórico, que marca uma cisão entre a vida intelectual e a vida concreta. É aquele que considera a realidade um estorvo e por isso teoriza o mundo sentado na poltrona. Todos os pensadores considerados por Scruton são, sem dúvida, teóricos de gabinete: o repúdio aos dados empíricos, à confirmação científica ou ao raciocínio que extravie o abstrato, lhes é transversal. Mas há algo nos pensadores da Nova Esquerda que os diferencia do usual intelectual de gabinete. Mais do que teorizar o mundo, esta nova massa pensante sente que precisa de mudar o mundo (no conforto da poltrona, claro). O intelectual de gabinete esvaia-se e surge o revolucionário de gabinete.

Introduzo este termo pois creio que grande parte do trabalho da Nova Esquerda assentou, ainda que inconscientemente, na criação e legitimação desta nova espécie. O intelectual deve ser um interveniente ativo da revolução: enunciando "absurdemas" e a sua náusea quanto a tudo que é "burguês", tem o mesmo papel emancipatório que o guerrilheiro proletário de AK47 em mãos. Através de teoria marxista, concluem o papel ativo do intelectual na revolução negando, contudo, a própria teoria marxista. Isto acontece, desde logo, com o pioneiro deste tipo de masturbação intelectual: Gramsci. Como Scruton nota brilhantemente, a teoria de hegemonia de Gramsci é, em si, uma negação do marxismo. Segundo o italiano, a burguesia estabelece uma hegemonia por toda a sociedade civil e no Estado. Ao controlar a educação, a comunicação social, a Igreja e afins, a burguesia perpetua sua ideologia, impedindo a concretização da revolução. Deste modo, a classe dominante torna-se imune ao abalo causado por crises políticas ou econômicas, pois a ordem social está em seu poder, propagado através da sua hegemonia. Ora, no meio deste raciocínio, que logo concluirá o imprescindível lugar do intelectual marxista na substituição da hegemonia burguesa, Gramsci nega o próprio determinismo marxista. O marxismo, que explica o desenvolvimento histórico como produto único de mudanças na infraestrutura econômica, é negado. Porém, o transe revolucionário impede que tais inconsistências incomodem seu autor. O mesmo tipo de incongruência estará também presente, por exemplo, em Althusser como o mesmo tipo de reação: nenhuma. 
A revolução de gabinete permanece como uma marca de água a todo o pensamento da Nova Esquerda e é crucial para a entender. Todas as artimanhas intelectuais, todos os maniqueísmos artificiais e todos os "absurdemas" são apenas passos rumo à legitimação do revolucionário de gabinete. Este trabalho intelectual acabará, em última análise, por se tornar a negação do próprio trabalho intelectual. Como Scruton narra brilhantemente, à medida que o revolucionário de gabinete se impõe, o pensador deixa de pensar, o ruminar de lugares comuns destrona a argumentação e a histeria revolucionária afirma-se como pensamento sério. E assim se pavimenta a estrada do absurdo.

Contudo, não creio que o transe revolucionário se aguente por si mesmo, muito menos que seja suficiente para explicar o rumo tomado pela Nova Esquerda. Embora Scruton o mencione poucas vezes, o livro torna-se mais claro quando entendemos o impulso religioso do marxismo (do pensamento de esquerda, grosso modo). O messianismo marxista (ou melhor, o messianismo progressista), descrito por Raymond Aron, Eric Voegellin ou até Karl Popper, é o verdadeiro motor da ação revolucionária e, quiçá, o unificador deste grupo heterogêneo de pensadores. Se dados são omitidos, se a crítica é ignorada ou se a argumentação é destituída, é porque a fé fala mais alto. A idolatria descrita no Velho Testamento surge como "reificação" ou "fetichismo", a salvação pela graça surge como salvação pela revolução e, no final de contas, o ópio do povo surge como ópio dos intelectuais.

O impulso religioso que sustenta o revolucionário de gabinete transparece das mais diversas formas na "Novilíngua" da Nova Esquerda. Scruton apropria-se do termo Orwelliano e este torna-se central na sua análise. A corrupção do pensamento depende sempre da corrupção da linguagem, e Scruton sabe isso melhor do que ninguém. Só uma linguagem reacionária se dedicaria à maçada de descrever a realidade. A linguagem revolucionária, a "Novilíngua", deve antes "exercer poder sobre a realidade". Tal projeto remonta, desde logo, aos primórdios da revolução soviética: só a "Novilíngua" permite caracterizar a maioria como menchevique (minoria). E tal arte tem sido aperfeiçoada a olhos vistos. A Novilíngua é o carvão da "máquina do absurdo", é a possibilidade da cisão absoluta com a realidade e a gênese de um pensamento onde ininteligibilidade se torna um mérito.

A restituição da sanidade depende da restituição da linguagem sã. O maior legado da Nova Esquerda é a desvirtuação da linguagem, algo que é profundamente mais perigoso do que qualquer reforma política ou social imediata. Só um mundo impregnado de "Novilíngua” pode teorizar o "feminicídio" sem vergonha de si mesmo. E pouco importa se as vítimas de cerca de 85\% dos homicídios cometidos no mundo são homens (WORLD HEALTH ORGANIZATION, 2015). A estatística (ideologia burguesa) jaz longe da Verdadeira Ciência. Com imaginação, adornamos a teoria com um "heteropatriarcado" aqui e uma "interseccionalidade" ali e, em pouco tempo, temos doutores a ser formados. A corrupção da inteligência só é possível quando o exercício da mesma é impossibilitado. Pensar o mundo com termos que não o definem é pensar o nada, e é exatamente isso que temos andando a pensar.

Ao ler o livro de Scruton, surgirão inevitavelmente certas questões: “Como é que alguém lia isto que x escreveu?" ou "Como é que x foi levado a sério?". Aos entusiastas do "marxismo cultural", lamento informar que não existe uma conspiração mundial marxista. É por nunca optar pela resposta fácil que o livro de Scruton responde à demanda por sanidade, inclusive da própria direita. $\mathrm{O}$ "marxismo cultural" não se diferencia em nada de uma teoria dos 
pensadores analisados: faz uso de um maniqueísmo artificial; pensa um mundo que, em vez de lutar contra a causa revolucionária, conjura contra a família e os bons costumes; e é, como o próprio marxismo, irrefutável: ao tentar demonstrar que certas instituições não estão dominadas por "marxistas". O comungante do marxismo cultural pode facilmente argumentar que tal afirmação só é possível pois fomos doutrinados pela própria instituição discutida. Vale lembrar Nietzsche (1992, p.176), "Aquele que luta com monstros deve acautelar-se para não tornar-se também um monstro. Quando se olha muito tempo para um abismo, o abismo olha para você". Que o abismo não nos olhe de volta.

\section{Referências}

NIETZCHE, F. Para além de bem e do mal. São Paulo: Companhia das Letras, 1992.

WORLD HEALTH ORGANIZATION. Homicide. WHO Global Health Estimates. Disponível em: http://apps. who.int/violence-info/homicide/. Acesso em: 1 jan 2018.

RECEBIDO EM: 02/11/18

APROVADO EM: 19/02/2019 